\title{
A MEMÓRIA DO NARRADOR: RESSONÂNCIAS TEMPORAIS ENTRE BENJAMIN, DELEUZE E BERGSON
}

Bruno de Seixas Carvalho

\begin{abstract}
RESUMO
Este artigo trata dos conceitos de experiência e narrativa inventados por Walter Benjamin, no intento de pensar o tempo sob suas intensidades e singularidade. Para tanto, produzirá traços de ressonância com a filosofia de Gilles Deleuze, extraindo a questão temporal como campo de consistência comum entre ambos os filósofos. A memória bersgsoniana, assim examinada por Deleuze, será mobilizada para funcionar como a memória do narrador e conquistar uma expressividade ética singular.
\end{abstract}

Palavras chave: tempo, experiência, narrativa e memória.

\section{THE MEMORY OF THE NARRATOR: TIME RESSONANCES BETWEEN BENJAMIN, DELEUZE AND BERGSON}

\begin{abstract}
This article tends to approach the concepts of experience and narrative invented by Walter Benjamin, with regards to think about time and its intensity and singularitie. For that, it will produce traces of ressonance with the Gilles Deleuze's philosophy, extratcting the issue of time as a field of comom consistency between both philosophers. Bergson's memory, as Deleuze examines, will be mobilized in order to function as the narrator memory and to conquest a singular ethic expression.
\end{abstract}

Keywords: time, experience, narrative and memory 


\section{INTRODUÇÃO}

O tempo é um problema filosófico deveras recorrente. De intensa notoriedade são as abordagens e produções discursivas que tentam dar conta do impacto prático a que esse tema acaba recorrendo. Entretanto, podemos notar certa saturação estrutural de preceitos lógicos reducionistas, espécie de fatalismos binários, essencialmente progressistas que vulgarizam, em última instância, a relação entre tempo e espaço. É necessário, portanto, uma perspectiva intempestiva da própria vida e dos devires que a compõem para ultrapassar a idéia asfixiante de que o futuro está dado, posto que seja uma mera sucessão do presente.

Nesse contexto, Walter Benjamin caracteriza-se por uma genuína autenticidade ao analisarmos com a devida minúcia alguns conceitos importantes como Experiência e Narrativa. Auto intitulado crítico literário, destaca-se por um estilo de prosa além das conjunturas formais estabelecidas, distante da tradição platônica essencialmente metafísica e, por isso, desconectado do excesso de cientificismo metodológico da própria filosofia. Benjamin consegue se aproximar da arte e sua potência criativa, seus ensaios são povoados de uma produtividade aberta, possibilitando ressonâncias múltiplas e linhas de fuga à contrapelo da história. Esse é o motivo de sua obra conseguir açambarcar as nuances temporais, apesar de não a abordar diretamente ou com tal finalidade.

Dessa forma, para extrair dos ensaios de Benjamin conceitos que nos ajudem a reformular os problemas sobre o tempo, analisaremos 0 funcionamento da Experiência em "Experiência e Pobreza" no intuito de estarmos à altura de como operava a Narrativa nas sociedades arcaicas e seu modo de produção de subjetividades. A seguir, faremos uma breve análise da modernidade e a partir de "O Narrador", exploraremos especificamente a questão da memória e de que maneira ela modula uma experimentação intensiva do tempo. Utilizaremos, para tal, um modelo de memória vislumbrado 
por Henri Bergson e desenvolvido por Gilles Deleuze, além de alguns conceitos estabelecidos por Deleuze e Guatarri em Mil Platôs, buscando uma aproximação entre a memória do Narrador e a memória bergsoniana.

\section{Particularidade e Singularidade}

Podemos observar em Walter Benjamin uma ausência de particularidade. Menos pela sua peculiaridade sobressaltada pela falta, do que, ao contrário, sua positividade por sua não-categorização formal. Ao se auto intitular crítico literário, vemos na prosa benjaminiana um desencaixe natural naquilo que ordinariamente se espera de um filósofo tradicional. É precisamente nessa zona cinzenta por onde perambulam os ensaios de Benjamin, que encontramos um ponto de vista, uma perspectiva própria que relativiza toda uma tradição lógico-formal. Não é que a falta, ou nãoformalização de Benjamin qualifique sua obra através de uma comparação com a estética formal ora vigente - e nesse sentido, nos perguntando "o que falta para se chegar a ela?"- é justamente essa ausência de forma prescrita que automaticamente instaura uma justa crítica ao que se entende pelas estruturas formais. Não são as formas vigentes que matizam o seu estilo, mas a sua própria falta de encaixe nessas formas que levantam questionamentos sobre elas. Eis uma inovação estética benjaminiana, cuja afirmação ajuda a explicar o porquê da demora de seu reconhecimento. Não há universalidade conceitual que a contenha.

Temos aqui um ponto importante, pois Walter Benjamin afasta-se da tendência filosófica platônica em buscar uma verdade incólume. Esta última costumeiramente travestida de um papel sumariamente julgador que atesta a validade do saber e é, assim, a portadora das luzes iluminadoras da racionalidade, da lógica e do caminho para o mundo das formas. Benjamin não segue esse script. Seus textos comportam uma série de metáforas abertas, onde coexistem inúmeros significados que se transmutam pela sua própria Oficial da Marinha do Brasil, formado pela Escola Naval, bacharel em Ciências Navais. PósGraduando em Filosofia Contemporânea na Pontifícia Universidade Católica do Rio de Janeiro (PUC-RJ) e Mestrando no Programa de Pós-Graduação em Estudos Marítimos da Escola de Guerra Naval (PPGEM-EGN). Brasileiro, residente no Rio de Janeiro-RJ. Email: 
descontinuidade teleológica. Há uma contradição lógica constante que afirma seu estilo, conforme Hannah Arendt destaca:

\begin{abstract}
Sua erudição era grande, mas não era um erudito; o assunto dos seus temas compreendia textos e interpretação, mas não era um filólogo; sentia-se muitíssimo atraído não pela religião, mas pela teologia e o tipo teológico de interpretação pelo qual o próprio texto é sagrado, mas não era teólogo, nem se interessava particularmente pela Bíblia(...) escreveu uma série de ensaios sobre autores vivos e mortos, mas não era um crítico literário; escreveu um livro sobre o barroco alemão e deixou um imenso estudo inacabado sobre o século XIX francês, mas não era historiador, literato ou que for... (ARENDT, 2008, p. 168)
\end{abstract}

Ora, o que seria esse diagnóstico se não a própria falência do método das divisões platônico? Benjamin repousa onde a lógica não alcança e é nesse sentido que poderíamos arriscar certa semelhança com Nietzsche e seus aforismos. Reforçamos assim sua singularidade em lugar de uma suposta particularidade, sendo esta última entendida como um possível subconjunto de uma generalidade já dada, preexistente.

\title{
2 A miséria da experiência
}

Os ensaios de Benjamin são especialmente interessantes quando os analisamos sob a perspectiva temporal. Alguns conceitos se destacam em sua obra, dentre os quais o de Experiência. De antemão, é importante ressaltar certo distanciamento da pergunta filosófica platônica "o que é isto?". Conforme explicitado, não há uma preocupação em dirigir conceito algum a uma universalização própria, de igual modo, inexiste qualquer aposta na racionalidade humana para alcançar qualquer definição generalista. O que se vê em "Experiência e Pobreza" e "O Narrador" é uma valsa metafórica que nos leva menos a atingir a essência formal de se transmitir tradições do que entender seu funcionamento; podemos dizer: sua operacionalidade através da vivência das experiências.

Oficial da Marinha do Brasil, formado pela Escola Naval, bacharel em Ciências Navais. PósGraduando em Filosofia Contemporânea na Pontifícia Universidade Católica do Rio de Janeiro (PUC-RJ) e Mestrando no Programa de Pós-Graduação em Estudos Marítimos da Escola de Guerra Naval (PPGEM-EGN). Brasileiro, residente no Rio de Janeiro-RJ. Email: 
Com efeito, não vamos encontrar em uma página sequer desses ensaios sentenças peremptórias tais como "A Experiência é isso...", ou "Para entender experiência precisamos antes saber o que é tradição...". No lugar, já nas primeiras linhas de "Experiência e Pobreza", Benjamin nos brinda com uma parábola, levando-nos a enxergar os modos de funcionamento da experiência:

\begin{abstract}
Em nossos livros de leitura havia a parábola de um velho que no momento da morte revela a seus filhos a existência de um tesouro enterrado em seus vinhedos. Os filhos cavam, mas não descobrem qualquer vestígio do tesouro. Com a chegada do outono, as vinhas produzem mais que qualquer outra na região. Só então compreenderam que o pai lhes havia transmitido certa experiência: a felicidade não está no ouro, mas no trabalho. (BENJAMIN, 2012, p. 123)
\end{abstract}

Vemos então a incapacidade latente dos filhos de, em um primeiro momento, conseguir acessar a mensagem a ser passada pelo velho moribundo. Fica aí uma contraposição de dois paradigmas antagônicos: o de um passado público, lutando para conservar-se através de um conselho tradicional diluído em uma revelação frugal; e de um presente privado, motivado pela recompensa final de um tesouro a ser encontrado - e é precisamente essa maneira de se enxergar a revelação do velho que motiva os filhos a irem cavá-lo para procurá-lo: eles põem-se a trabalhar não pelo trabalho em si, mas pela busca do tesouro, numa perspectiva objetiva da vida. Dragados pela teleologia de uma experiência miserável, os filhos, apesar de fisicamente próximos ao seu pai, distanciam-se dele. Foi preciso experimentar a revelação para entendê-la, o velho sabia que seus filhos iriam interpretá-la antes de senti-la, sabia que simplesmente dizer que o trabalho é importante não seria suficiente, porque a experiência narrada e a experiência vivida encontravam-se em dimensões temporais diferentes.

Apesar disso, cumpre ressaltar que não há aqui qualquer tipo de valoração comparativa, referente aos paradigmas ora expostos. Benjamin não se apega a dizer se o velho está certo ou se seus filhos o estão. Há sim um diagnóstico que ultrapassa problematizar a questão da experiência em moldes

Oficial da Marinha do Brasil, formado pela Escola Naval, bacharel em Ciências Navais. PósGraduando em Filosofia Contemporânea na Pontifícia Universidade Católica do Rio de Janeiro (PUC-RJ) e Mestrando no Programa de Pós-Graduação em Estudos Marítimos da Escola de Guerra Naval (PPGEM-EGN). Brasileiro, residente no Rio de Janeiro-RJ. Email: 
positivos ou negativos. Aqui há uma demonstração de que a experiência não é mais como era antigamente - nas sociedades arcaicas -, a tradição oral já não atinge os mesmos efeitos, já não é capaz de colocar uma pitada de passado no presente e produzir subjetividades. Já não há tanto um senso de comunidade capaz de tornar a experiência algo significativo a ponto de dar e receber conselhos, a ponto de transmitir tradições. Há uma pobreza de experiência.

Apesar de um tom por vezes nostálgico, Benjamim nos mostra que a decadência da experiência não é seu assassinato - por um sujeito a quem será atribuído a culpa -, não é uma ruptura brusca fatalmente associada a uma causa unívoca, não é o fim de um acontecimento que enseja uma nova geração de experiências ruins, será um processo rizomático, no nível molecular ${ }^{1}$ mesmo, concretamente imperceptível, mas que se sente. Ademais, pobreza aqui estará estritamente associada à escassez: uma experiência pobre será uma experiência pouca, desmentida, tal como a inflação o é para a experiência econômica. É justamente por isso que Benjamin foi extremamente preciso em utilizar a expressão Barbárie Positiva para se referir a esse processo. Ou seja, é uma produtividade da falta, uma destruição impulsionadora, uma obrigação intrínseca de criar algo novo, de se trabalhar em uma tábua rasa, como numa prancheta. Tal qual um bárbaro, a mudança paradigmática da experiência condicionará 0 surgimento de novas perspectivas. Devemos assinalar, todavia, que o novo estará para além de uma mera síntese de tudo que anteriormente já foi dado, e ele exemplifica tal aspecto em Descartes.

\footnotetext{
1 Estamos aqui nos referindo ao conceito de rizoma presente em Mil Platôs, no platô número 1, chamado Manifesto rizoma. Queremos dizer que a experiência pode ser encarada como um processo produtivo múltiplo, fora de uma causalidade fatalista ou uma linearidade teleológica. A experiência rizomática seria aquela dotada de uma ética intensiva de experimentações, seu espraiamento dar-se-ia como que por contágio. O rizoma é a própria multiplicidade das multiplicidades, capaz de abolir qualquer profundidade que desliza a vida dela mesma. Molecular, da mesma forma é a imperceptibilidade de um processo real, que não pode ser concretamente concebido e que escapa da lógica consensual de conectar efeitos a causas. Tal seria a experiência de que falamos, aquela capaz de mobilizar mundos, mas que se esvai pelas mãos ao tentar materializa-la.
}

Oficial da Marinha do Brasil, formado pela Escola Naval, bacharel em Ciências Navais. PósGraduando em Filosofia Contemporânea na Pontifícia Universidade Católica do Rio de Janeiro (PUC-RJ) e Mestrando no Programa de Pós-Graduação em Estudos Marítimos da Escola de Guerra Naval (PPGEM-EGN). Brasileiro, residente no Rio de Janeiro-RJ. Email: 
Dessa maneira a experiência como sendo essa capacidade de imbricar as vivências pessoais em um todo mais ou menos homogêneo, em uma comunidade onde não há tanta distinção entre o público e o privado, encontrou seu declínio. Mais adiante entenderemos o porquê desse processo como resultado da evolução da técnica. Por ora, diremos que Benjamin em "Experiência e pobreza" está falando da transfiguração de uma comunidade pública em individualidades privadas, de uma cultura de veludo em uma cultura de vidro. Há inclusive uma passagem que denota essa diferença:

\begin{abstract}
Se entramos num quarto burguês dos anos oitenta, apesar de todo o aconchego que ele irradia, talvez a impressão mais forte que ele produz se exprima na frase: "Não tens nada a fazer aqui". Não temos nada a fazer ali porque não há nesse espaço um único ponto em que seu habitante não tivesse deixado seus vestígios (...). Essa atitude é a oposta da que é determinada pelo hábito, num salão burguês. Nele, o "interior" obriga o habitante a adquirir o máximo possível de hábitos, que se ajustam melhor a esse interior que a ele próprio (...) Tudo isso foi eliminado por Scheerbart com seu vidro e pelo Bauhaus com seu aço: eles criaram espaços em que é difícil deixar rastros. "Pelo que foi dito", explicou Scheerbart há vinte anos, "podemos falar de uma cultura de vidro(...) (BENJAMIN, 2012, p. 127)
\end{abstract}

Por que, no cômodo burguês, "Não temos nada a fazer ali"? Como diz Benjamin, sequer há espaço onde não haja vestígio de seu hóspede. É um ambiente carimbado pelo seu habitante, fica impossível andar por aquele lugar sem haver referência a quem esteve ali, sem associar cada parte daqueles bibelôs ao seu dono. São vestígios que imprimem sobre cada espaço uma assinatura imaginária, porém com efeitos reais e práticos. É como se o quarto burguês, naquela saturação inebriante de detalhes, naquela impregnação opressora de objetos e cores, fosse a continuidade de quem fica ali, uma extensão conjunta, marcas que conectam e codificam. Se não se pertence aquele cômodo, se ele não é seu, isso já não precisa sequer ser trazido à consciência porque existe uma fronteira implicitamente explícita, menos cognoscível do que sensível. Aqui não se trata mais de ação, não há o que fazer, é uma imobilização automática, somos drenados ao universo de um todo que abraça, contorce e molda - como quando repousamos a mão sobre uma

Oficial da Marinha do Brasil, formado pela Escola Naval, bacharel em Ciências Navais. PósGraduando em Filosofia Contemporânea na Pontifícia Universidade Católica do Rio de Janeiro (PUC-RJ) e Mestrando no Programa de Pós-Graduação em Estudos Marítimos da Escola de Guerra Naval (PPGEM-EGN). Brasileiro, residente no Rio de Janeiro-RJ. Email: 
superfície de veludo por alguns minutos. Nesse caso, esse todo tem um dono e entramos no mundo dele.

Agora, já no Salão burguês, apesar de uma exigência diferente por quem quer que esteja ali dentro, ocorre um funcionamento semelhante. Benjamin diz: "o interior obriga o habitante a adquirir o máximo possível de hábitos", ou seja, é um protagonismo do meio também, que englobante, imprime a quem estiver ali um impulso para se conseguir habitar, uma tendência a querer se ajustar mais àquele lugar do que se ajustar em si próprio. O Salão burguês acaba "fagocitando" os sujeitos e imperando sob a égide suas marcas perenes. Aqui não mais pelo dono, mas pela própria medida que o seu denso espaço mobiliza. Veja que há uma contradição de comportamentos que afirma o próprio traço característico dessa tal cultura de veludo. Dito de outra forma, a própria arquitetura dos lugares denota a prevalência da comunidade sobre o indivíduo, do público sobre o privado, da experiência comum sobre a vivência privada.

É justamente para comparar esse aspecto que Benjamin faz referência a Bauhaus e à cultura de vidro. Vemos um ambiente que se impõe e traz o sujeito para si contraposto a um ambiente minimalista, tábua rasa, liso, de vidro, onde o próprio significado e seus traços agora serão erigidos pelo próprio sujeito no interior de suas próprias vivências. É esse sujeito que trará o meio para si, sem sequer precisar modificá-lo. Por isso, o Salão de Vidro não mais vai arrastá-lo para si, será, ao contrário, configurado no interior de cada individualidade e suas vivências. Não há o que ser modificado, porque é um espaço que não deixa marcas. O tesouro não mais será uma riqueza compartilhada por uma comunidade que precisa que todos trabalhem a terra para sobreviverem em conjunto, o tesouro será o dinheiro, na medida em que ele será a via de aquisição de uma riqueza individual. 


\section{A Narrativa de Benjamin}

Se há uma crise de vivenciar e compartilhar experiências, o declínio em sua transmissão e atualização será um resultado correlato. Dessa maneira, o principal impacto a que Benjamin se refere em "O Narrador", será justamente a perda da habilidade em se narrar. É importante atentarmos para o fato de que, tal qual o conceito de experiência, não se resume a sua denotação consensual; não será simplesmente descrever um fato distante dos acontecimentos que o ensejaram. Existe uma singularidade artística na narrativa benjaminiana, algo que se substantiva na medida em que se afirma.

Nesse sentido, a narrativa aqui considerada deve ser entendida como uma experiência ética, para além de ser interpretada, ela requer que seja vivida. O Narrador sente o tempo através de sua memória, atualiza e transmite tradições em uma moral aberta, imanente, construída pelos próprios agenciamentos $^{2}$ com seus ouvintes. Estamos falando de subjetividades, de multiplicidades de diferenças afirmadas no lugar de sujeitos enunciadores da verdade. Se a técnica veio para equalizar posturas, a narrativa, antecedendo essas estruturas, veio para consolidar costumes.

Benjamin elege como tipos fundamentais os camponeses sedentários e os marinheiros viajantes. Ora, podemos verificar claramente a potência desterritorializadora ${ }^{3}$ dos marinheiros em seus barcos, multidões de homens de todos os lugares que juntos incorporavam em suas experiências tradições

\footnotetext{
2 Conceito desenvolvido por Gilles Deleuze e Felix Guatarri. Segundo Maurizzio Larazatto, em Signos, Máquinas e Subjetividades, o agenciamento é um processo através do qual as subjetividades de um indivíduo (como inteligência, afetos, cognição, força física, memória, consciência) não são mais centralizadas em um "eu" de um sujeito individuado como referente. Tais subjetividades condensam-se por sobre um processo contínuo, onde cada pessoa funciona como uma engrenagem imanente ao coletivo. O agenciamento é justamente essa aglutinação fluída de indivíduos "desindividuados". É o processo em si.

${ }^{3} \mathrm{O}$ conceito de desterritorialização encontra-se relacionado ao conceito de devir, na filosofia de Deleuze e Guatarri. Queremos dizer com isso que desterritorializar é fazer-se fugir dos moldes institucionais previamente estabelecidos, é escolher a escolha, é estar a altura do futuro. Os marinheiros podem ser considerados como que afetados por esse processo uma vez que, de saída, já vivem sob um regime de constante mudança de lares e de ambientes.
}

Oficial da Marinha do Brasil, formado pela Escola Naval, bacharel em Ciências Navais. PósGraduando em Filosofia Contemporânea na Pontifícia Universidade Católica do Rio de Janeiro (PUC-RJ) e Mestrando no Programa de Pós-Graduação em Estudos Marítimos da Escola de Guerra Naval (PPGEM-EGN). Brasileiro, residente no Rio de Janeiro-RJ. Email: 
longínquas de mais uma multidão de lugares, não sem ganharem expressividade nos próprios agenciamentos e subjetividades que construíam no interior de suas embarcações. Marinheiros viajantes são rizomas, juntos, agenciamentos de expressão. Já os camponeses ao contrário, apresentam-se como uma potência territorializante, precisam trabalhar a terra e compartilhar seu conhecimento. Mas aí mesmo existe uma conexão que a técnica não atinge. É preciso sentir a terra, a relação terra-agricultor é uma servidão maquínica ${ }^{4}$ produzindo subjetividades outras que movimentam o costume compartilhando experiências.

Por isso, Benjamin afirma que "Entre as narrativas escritas, as melhores são as que menos se distinguem das histórias orais contadas pelos inúmeros narradores anônimos". A oralidade e o anonimato do narrador estão relacionados com a sua própria relação com o tempo e muito por isso são traços característicos que o distinguem. Eis um ponto importante. Como veremos mais adiante, o tempo em que Benjamin vive é o ápice do tempo científico, o tempo do Deus morto, esquartejado em intervalos finitos e, portanto, descontínuo. É o fim do século XIX e começo do XX, cúmulo das linhas de montagens, do fordismo; quando a sucessão de momentos instantâneos se protagoniza no lugar dos momentos em si. O tempo só fazia sentido se tivesse um sentido, este que se reduziu a vincular um determinado espaço a uma determinada velocidade em ordenação progressiva. Em uma primeira análise formal, o narrador, aquele capaz de comunicar sua experiência, será ele mesmo um vínculo e também a condição de continuidade de um tempo de outrora, um tempo arcaico.

\footnotetext{
${ }^{4}$ Felix Guatarri desenvolve esse conceito buscando descentrar do sujeito sua relação com o objeto. A ideia de uma servidão maquínica procura desvencilhar-se tanto de uma servidão como pura obediência e submissão, quanto de um maquinismo unicamente mecânico, operando conforme a soma quantitativa de todos as partes. Uma servidão maquínica, ou um maquinismo, nos termos de Guatarri, é uma conexão fluída que ultrapassa o mimetismo, de modo que tanto a terra afeta o agricultor quanto este a afeta, gerando uma singularidade compreendida no universo entre ambos. Desse processo resultam as subjetividades.
}

Oficial da Marinha do Brasil, formado pela Escola Naval, bacharel em Ciências Navais. PósGraduando em Filosofia Contemporânea na Pontifícia Universidade Católica do Rio de Janeiro (PUC-RJ) e Mestrando no Programa de Pós-Graduação em Estudos Marítimos da Escola de Guerra Naval (PPGEM-EGN). Brasileiro, residente no Rio de Janeiro-RJ. Email: 
O tempo então estará embebido na própria arte de narrar, e o narrador, além de incorporar suas próprias experiências, "será capaz de incorporar as coisas narradas à experiência dos seus ouvintes". Nesse ponto, destaca-se o aspecto oral da narrativa. A fala diz respeito a uma quase pureza técnica, onde o narrador, também com seu próprio corpo, modula a substância narrada, "deixando sua marca como o oleiro na argila do vaso". E somente a oralidade traria essa característica, ela possibilitaria:

\begin{abstract}
A alma, o olho e a mão estarem inscritos num mesmo contexto, eles definem uma prática(...). Pois a narração não é produto exclusivo da voz. Na verdadeira narração, a mão intervém decisivamente, com seus gestos, aprendidos na experiência do trabalho, que sustentam de cem maneiras o fluxo do que é dito. Podemos ir mais longe e perguntar se a relação entre o narrador e a sua matéria - a vida humana - não seria ela própria uma atividade artesanal. (BENJAMIN, 2012, p. 239)
\end{abstract}

Benjamin, portanto, quer dizer que a própria atividade de narrar produz um falar próprio que se desprende da voz, que se agencia, que ganha expressividade fazendo o corpo impulsionar as conexões de experiência. Talvez haja aqui um afastamento do modus operandi científico, este último entendido como uma divisão de tarefas que objetivamente segrega os sentidos e as sensações em partes específicas do organismo. Para Benjamin, nada está dado, as narrativas envolvem servidões maquínicas, construção de subjetividades e não de sujeitos. Por isso, a fala irá muito além de simplesmente utilizar a boca. Narrar é cantar com as mãos, é dizer com os olhos, é balbuciar sílabas com os mínimos gestos, é criar uma linguagem dentro da própria linguagem, é talhar um ritmo na própria matéria do que é dito, é produzir subjetividades práticas que enlaçam narrador e ouvinte. O narrador é um artesão e, como tal, precisa falar com as mãos e deixar seu discurso em suas obras, para isso, mergulha no tempo e o conduz.

Nesse sentido, convém sublinharmos o eventual reducionismo em se considerar o Narrador como um sujeito tipicamente individualizado e racionalmente responsável por tal processo. Isso seria formular um problema

Oficial da Marinha do Brasil, formado pela Escola Naval, bacharel em Ciências Navais. PósGraduando em Filosofia Contemporânea na Pontifícia Universidade Católica do Rio de Janeiro (PUC-RJ) e Mestrando no Programa de Pós-Graduação em Estudos Marítimos da Escola de Guerra Naval (PPGEM-EGN). Brasileiro, residente no Rio de Janeiro-RJ. Email: 
ético em termos epistemológicos. Precisamos ultrapassar o corpo, porque não se trata somente do corpo físico, e tampouco de uma memória pessoal, mas sim de um corpo público, um encontro de forças afetivas, Corpo Sem Órgãos ${ }^{5}$, como queriam Deleuze e Guatarri. Entretanto, antes de trazer à tona tal conceito e relacioná-lo à figura do narrador e ao problema do tempo, precisamos entender para onde se dirige nossa crítica, no sentido de conhecer o modelo de tempo que pretendemos ultrapassar.

\section{Considerações sobre o tempo}

Uma vez mais, ressaltemos a perspectiva temporal moderna em que se consubstancia a sucessão de instantes como paradigma central. Do que estamos falando exatamente? A revolução tecnológica que tomou forma no ocidente, sobretudo a partir de Galileu e Newton reformulou questionamentos importantes e inaugurou uma nova percepção temporal. Se na antiguidade constatávamos um tempo cíclico, onde o herói grego é constrangido pelo destino e tudo está dado pela ação deste, na modernidade nos deparamos com um tempo progressivo, quando a ciência busca previsibilidade, padrões. Assim, calcado numa lógica indutiva, capaz de imiscuir acontecimentos semelhantes negando suas diferenças, o tempo científico construirá eventos idênticos e amplificá-los-á para um horizonte tão grande quanto se queira. Tomando como referência a época em que Benjamin viveu e evolução da técnica até então, desde as leis gravitacionais de Keppler até as equações de Ondas eletromagnéticas de Maxwell, passando pela própria teoria evolucionista de Darwin, a ciência escorou-se em um binarismo clássico para

\footnotetext{
5 Deleuze se utiliza desse conceito a partir de Antoine Artaud, buscando ultrapassar 0 organismo, ou seja, o corpo com seus órgãos e seus papeis previamente definidos, operando em conjunto. Em verdade, trata-se de analisar o corpo não necessariamente material, mas como devir, como o que não se alcança, diferenças de diferenças limítrofes. O Corpo Sem Órgãos é uma experimentação dos bons encontros, é conquistar o devir a partir dos bons encontros.
}

Oficial da Marinha do Brasil, formado pela Escola Naval, bacharel em Ciências Navais. PósGraduando em Filosofia Contemporânea na Pontifícia Universidade Católica do Rio de Janeiro (PUC-RJ) e Mestrando no Programa de Pós-Graduação em Estudos Marítimos da Escola de Guerra Naval (PPGEM-EGN). Brasileiro, residente no Rio de Janeiro-RJ. Email: 
apontar o tempo para um destino inexorável, rumo a um futuro timidamente possível. De uma maneira geral, podemos assumir raízes profundas na tradição platônica: o igual e o diferente, a verdade e a mentira, o verdadeiro e o falso, mundo das cópias, mundo das formas, a luz e a escuridão. Kant denuncia as falsas pretensões do conhecimento, mas não analisa a própria faculdade de conhecer, a própria dialética hegeliana converge a uma síntese onde tudo também já estaria dado.

Dessa maneira, o consequente formalismo lógico baseado em leis universais estruturou uma especialização científica tão intensa que a própria natureza passou a ser humanizada de modo a obedecer a essas mesmas leis. Não é difícil então entender o otimismo ocidental no final do século XIX: O homem conquistaria o mundo utilizando como ferramenta a ciência. $O$ diagnóstico nietzschiano de que "Deus está morto" serve para mostrar nem tanto que a ciência preenchia agora um papel metafísico antes destinado a Deus, mas sinalizar que o homem agora poderia reservar-se, como indivíduo racional, ao papel de Deus. Ou seja, a modernidade trouxe uma reformulação da relação Deus-Sujeito, certo antropocentrismo, em que o homem humaniza também o conceito de Deus. Deus está morto, pois colocamos o homem em seu lugar (DELEUZE, 2016, 21). O tempo seria um desses sintomas se o enxergarmos como uma variável intrinsecamente relacionada, padronizada, identificada e dependente de outras tais como o espaço. Se junto a isso somarmos a necessidade lógica do binarismo verdadeiro-falso, entenderemos a progressão temporal moderna: um instante no tempo poderá ser determinado a partir de um ponto no espaço com determinada aceleração e velocidade. Esse mesmo instante não poderá ser outro. Em outras palavras, é verdadeiro que esse instante seja ele mesmo, porque se não for, será falso e assim somente poderá ser 0 anterior ou o posterior. O próprio tempo automaticamente já se encaixa em uma ordem previsível: será o antes ou o depois, o futuro ou o passado. 
Em verdade, esse modelo restringe o tempo a um mecanicismo tal que, numa hipótese absurda, se tivéssemos posse de uma equação com todas as variáveis de que precisássemos, conseguiríamos dar conta do futuro, ele já estaria dado bastando apenas calculá-lo. O que talvez se configure uma contradição, pois o futuro já existiria no presente, uma vez que podemos antevê-lo, não saindo, portanto, do presente. Analogamente, podemos raciocinar o mesmo com o passado. Portanto, a diferença entre passado, presente e futuro seria meramente formal, simples gradação numérica, diferença de grau, conforme Bergson assinala. Além disso, uma consequência correlata poderá ser levantada: o passado se resume a ser um presente que já foi, ou seja: o presente precisa deixar de ser para transformar-se no momento que o antecede, agora passado e que, por conseguinte, será reconstituído para formar um novo presente (DELEUZE, 2012). Estamos diante de uma representação marginalizada do tempo; uma leitura simplificada para aplicar os efeitos temporais na vida prática, saímos do tempo para entendê-lo, tal qual no Mênon, Sócrates precisa do sólido para definir a figura.

\subsection{O paradoxo do tempo}

Segundo Bergson e Deleuze, conforme analisado em Bergsonismo, enxergar o presente, passado e futuro como mera sucessão de eventos é reduzir a questão a um falso problema, a um misto mal analisado, é dissolver as diferenças qualitativas em identidades espaciais homogêneas. Bergson procura desvencilhar-se desse modelo, uma vez que considera passado e presente como elementos de naturezas distintas, como duas séries que divergem entre si, mas que coexistem e jamais poderiam confundir-se. Deleuze ainda acrescenta que o futuro seria um devir-futuro, aquilo que não está dado e que talvez possa jamais acontecer. O rigoroso método intuitivo bergsoniano, extrapolando a formalidade da inteligência e pondo-a a serviço da espontaneidade natural do instinto a favor da vida, inaugura o conceito de Oficial da Marinha do Brasil, formado pela Escola Naval, bacharel em Ciências Navais. PósGraduando em Filosofia Contemporânea na Pontifícia Universidade Católica do Rio de Janeiro (PUC-RJ) e Mestrando no Programa de Pós-Graduação em Estudos Marítimos da Escola de Guerra Naval (PPGEM-EGN). Brasileiro, residente no Rio de Janeiro-RJ. Email: 
Duração, e a partir dele procura estabelecer justos conceitos, como um alfaiate procura coser justas roupas - e não roupas justas. Um exemplo bastante recorrente em Evolução Criadora é o da dissolução do açúcar na xícara de café. Encontramos aí um tipo de tempo quantitativo quando, por exemplo, contamos no relógio os minutos que levam para o açúcar dissolver-se totalmente. Esperamos que ele se dissolva e medimos a espera por minutos. Mas existe ainda outro tipo de tempo, o tempo a que Bergson efetivamente se refere, ultrapassando o espaço compreendido por apenas contar algarismos representativos. Aqui, também esperamos que o açúcar se dissolva, mas ao fazê-lo, encontramos, ou melhor, produzimos, uma multidão de devires, de sensações e tendências que tornam a espera recheada de emoções. Tal experiência só será alcançada se conseguirmos sair de nossa própria Duração e estar à altura das multiplicidades outras - e não várias - que coexistem e diferenciam-se junto com a nossa. Dessa maneira, aguardar o café adoçar poderá ser inteiramente diferente, ou seja, a diferença qualitativa de tempo para um mesmo indivíduo, apesar de contado os mesmos minutos, pode resultar em experiências completamente distintas.

É precisamente desse tempo que estamos falando quando tentamos escapar da espacialização da vida. E é por isso que interessa aqui sublinhar a diferença de natureza entre passado e presente. Ora, como o presente consegue deixar de ser presente sem, em seguida, virar passado? Como o presente poderá passar e ainda sim ser presente? Eis um grande paradoxo temporal que demonstra a fragilidade da perspectiva espacial moderna e possibilita a seguinte constatação: o presente jamais poderia passar se ele não fosse, de saída, também o passado, e o passado por sua vez jamais se constituiria como tal, se também não fosse, de igual modo, o presente. Em outras palavras: em lugar de pensar numa sucessão entre passado e presente, vislumbrar, na realidade, a coexistência de ambos, o passado é "contemporâneo do presente que ele foi" (DELEUZE, 2012, 50). Ressaltemos que não se trata de uma mistura homogênea imperceptível entre ambos, mas 
sim de dois blocos de multiplicidades que se diferenciam entre si e em si, mas que não se misturam. O presente será uma tendência que não para de passar e o passado, que não para de ser, um "estar sendo" que "tem sido". Oportuno aqui enfatizar que na hipótese nos perquirirmos acerca de um ordenamento entre ambos, no sentido de tentar encontrar quem viria primeiro, ou, buscar a origem do presente ou do passado, seria cair, novamente, em um falso problema, pois estaremos espacializando uma vez mais o tempo. Tal evidência corrobora-se se percebermos que uma ordem requer parâmetros, que por sua vez, requerem medidas, estas que nada mais são do que representações do espaço.

\subsection{A memória Bergsoniana como a memória do Narrador}

Dessa maneira, conseguimos nos afastar de um lugar-comum deveras recorrente. Podemos relacionar a coexistência de passado e presente com uma flagrante desconstrução da ideia de memória como simples reservatório de lembranças, como um grande espaço preenchido de recordações, como a resposta para o lugar aonde iria o presente que passa. A questão "para onde vão as lembranças?" torna-se desnecessária, pois estamos conferindo uma substância tal para o tempo, que não há espaço que o contenha. O passado não vai para lugar algum, ele simplesmente já é - outro paradoxo: um passado que é - e existe na mesma medida que o presente está passando. Com isso, diremos que as lembranças se conservam em si. Significa dizer que a totalidade de nossa memória acompanha nossa existência no presente e, estar existindo é somente uma parte mais consistente, mais concentrada desse amalgama temporal. Algo como um ponto conspícuo de uma nuvem cinza infinita. Tudo que vivemos nos constitui e nos desconstrói à medida que vivemos, em um fluxo aberrante que não está dado. Existe uma diferença produtiva na repetição e no eterno retorno Nietzschiano que Deleuze e Guatarri 
denominam Ritornelo ${ }^{6}$. Uma voz são muitas vozes, uma lágrima são infinitas lágrimas, uma fala são múltiplas falas. Tempo é rizoma, tempo é ritornelo.

Todavia, apesar dessa dimensão temporal que a memória abrange, algo ainda nos impele a agir, ainda existe uma utilidade na vida prática, no presente, que faz parte de nossa existência. Bergson argumenta que nossos sentidos, regulados pelo que ele denomina esquema sensório-motor, recortam a realidade de acordo com a utilidade atribuída à matéria. Nesse ponto, relembramos a crítica de Benjamin em "A imagem de Proust" denunciando certo voluntarismo da memória. Conforme veremos no próximo item, embora contenha um aspecto finalista, seria impreciso atribuir um caráter voluntário à memória bergsoniana. Dessa forma, a pergunta que nos importa agora é: Se a memória trabalha no presente, como ela se atualiza nele?

\subsection{A memória inconsciente}

Para entender esse processo, Bergson descreve um modelo de memória inconsciente, porém em um sentido que se distancia da perspectiva psicanalítica. Com efeito, memória inconsciente significa dizê-la como uma realidade não psicológica, totalmente distinta da psiquè individual freudiana singularmente ativa e eficaz. Eis o motivo da imprecisão ao considerá-la voluntária: não se trata de uma ação pautada pela consciência individual, dado que esta será justamente o resultado da atualização da memória. Estamos falando do antes, estamos falando do passado mesmo, do Ser em si que antecede as atualizações do presente. A consciência é o presente. Mas como

\footnotetext{
${ }^{6}$ Ritornelo para Deluze e Guatarri é um processo múltiplo, advindo da palavra "retorno" em italiano ritorno. Tal processo consiste em três fases. A primeira denominada do caos a casa, é quando territorializa-se determinado acontecimento. A seguir, da casa ao cosmos, é quando tal processo ganha expressividade. Por último, do cosmos a terra, buscando evidenciar o retorno diferenciador. Para Deleuze, o eterno retorno niestzschiano é identidade da diferença, é a própria diferença se afirmando e desterritorializando-se. Podemos, da mesma forma, considerar o tempo com essa mesma potência cíclica e repetitiva mas ao mesmo tempo criadora.
}

Oficial da Marinha do Brasil, formado pela Escola Naval, bacharel em Ciências Navais. PósGraduando em Filosofia Contemporânea na Pontifícia Universidade Católica do Rio de Janeiro (PUC-RJ) e Mestrando no Programa de Pós-Graduação em Estudos Marítimos da Escola de Guerra Naval (PPGEM-EGN). Brasileiro, residente no Rio de Janeiro-RJ. Email: 
entender a memória fora da realidade psicológica do indivíduo? Precisamos enxergá-la não como um problema do conhecimento ou da racionalidade/nãoracionalidade, mas como uma questão Ontológica, Bergson coloca a memória como uma realidade ontológica, para além da individualidade do sujeito ${ }^{7}$. Não nos parece necessário descrever os pormenores de todo esse mecanismo, tal qual é demonstrado em Matéria e Memória e em Bergsonismo. Todavia, é necessário destacar a virtualidade do passado enquanto memória. Essa memória virtual poderá ser visualizada como um cone invertido, onde seu ápice será o ponto de intersecção com o presente. Ela estará inteiramente contida em cada um de seus diversos níveis, contraídos consoante ao que o presente requerer. Acessar tais níveis significa dar um salto, mas não um salto qualquer, um salto qualitativo, ontológico que de saída já nos coloca no passado em si. Apesar de aparentemente abstrata, essa constatação é deveras prática e avassaladora: ao invés de irmos do presente ao passado, para invocar a memória, o percurso será do passado ao presente.

Podemos voltar ao exemplo da dissolução do açúcar no café. Durante a espera, nosso olfato, aqui entendido como uma das partes do esquema sensório-motor, recortará uma própria característica do aroma da bebida. Necessidade do presente, portanto. Então, de saída, nos instalaremos em um nível mais contraído de nossa memória e dele resgataremos uma lembrança. $A$ atualização, a consciência, o retorno ao presente dessa lembrança, por completo, já lhe confere uma mudança de natureza. Dessa atualização resultará a impaciência, ansiedade, leveza, ou qualquer outra emoção oriunda da simples espera pelo açúcar se dissolver. O salto na memória é um mergulho no tempo, mas um tempo que não pode ser medido e que produz uma Duração

\footnotetext{
7 Deleuze assume a influência platônica de Bergson, porém, como veremos, esse modelo ontológico ainda necessita do presente para ser, coexistindo com ele. Talvez essa seja a resposta de Bergson à Sócrates no Parmênides, quando este diz: "Mas se aquilo que é realmente um, alguém demonstrar que isso mesmo é múltiplas coisas, e, de outra parte, que $o$ múltiplo é um, já disso me espantarei". Eis o ponto: o passado e o presente são. Um é múltiplo para Deleuze.
}

Oficial da Marinha do Brasil, formado pela Escola Naval, bacharel em Ciências Navais. PósGraduando em Filosofia Contemporânea na Pontifícia Universidade Católica do Rio de Janeiro (PUC-RJ) e Mestrando no Programa de Pós-Graduação em Estudos Marítimos da Escola de Guerra Naval (PPGEM-EGN). Brasileiro, residente no Rio de Janeiro-RJ. Email: 
qualitativa especialmente singular. Como comparar uma impaciência com outra? Uma ansiedade com outra? Um amor com outro? Cada experiência particular será repaginada com outras cores, outras sensações, outros sentimentos, é todo o passado que será transfigurado e implicará nas ações do presente: um eterno retorno da diferença. Cada franja do presente revoluciona todo o oceano do passado. As bordas amareladas das fotografias somente materializam o passado daquele presente que ele foi.

\subsection{O tempo do Narrador}

Consideraremos então que seja desse tempo, dessa memória, desse esquema ontológico que ultrapassa o telos fatalista moderno que Benjamin se refere quando fala do Narrador, pois sua arte de transmitir experiência ultrapassa a mera coleção de instantes. Ele não viverá no tempo, viverá o próprio tempo, em uma constante atualização da tradição comunitária. O Narrador benjaminiano precisará dar também um salto ontológico na memória comunitária para atualizar tradições e transmiti-las. Precisará sair de sua Duração e penetrar na Duração do ouvinte. Portanto, ele não será um sujeito atravessado por predicados, senhor de uma existência infinitesimal, justaposta a uma heterogeneidade outra de indivíduos que somados darão a comunidade. Pouco importa a minúcia de detalhes a ser explicitada, porque não se trata do ponto de vista do narrador, trata-se da vastidão cultural da comunidade atualizada através do narrador. Seu corpo será uma maior consistência de toda a virtualidade do passado da comunidade mesma, donde a perenidade dos costumes atualizados significará a produção de diferenciações de diferenças desses mesmos costumes. Tradições como tendências e não como valores metafísicos idealizados e incólumes. Agora fica claro por que Benjamin ressalta o enxugamento de sutilezas psicológicas na fala do Narrador, a memória como realidade inconsciente não poderia reter-se em análises psicológicas. Daí o anonimato: não há nome que reduza a virtualidade de uma memória comunitária a um sujeito individualizado, um narrador são infinitos narradores, Oficial da Marinha do Brasil, formado pela Escola Naval, bacharel em Ciências Navais. PósGraduando em Filosofia Contemporânea na Pontifícia Universidade Católica do Rio de Janeiro (PUC-RJ) e Mestrando no Programa de Pós-Graduação em Estudos Marítimos da Escola de Guerra Naval (PPGEM-EGN). Brasileiro, residente no Rio de Janeiro-RJ. Email: 
a arte de narrar é rizomática, a memorização se dá por contágio, e não nos contagiamos com sutilezas calculadas, é como diz Benjamin:

\begin{abstract}
Nada facilita mais a memorização das narrativas do que aquela sóbria concisão que as subtrai à análise psicológica. E quanto maior a naturalidade com que o narrador renuncia às sutilezas psicológicas, tanto mais facilmente a história será gravada na memória do ouvinte. (BENJAMIN, 2012, p. 220)
\end{abstract}

\title{
5 Bons encontros e ascensão da técnica
}

O Narrador de Benjamin é o narrador dos encontros, não dos cálculos discursivos e das medições. Não basta contar como foi e deter-se na verossimilhança de um passado representativo. A interpretação da fala narrativa é muito pouco, é preciso fazê-la atingir o ouvinte, é preciso experimentá-la, mais uma vez, sair de sua Duração. Transmitir tradições é tornar consistente todo um plano de afetos entre quem fala e quem escuta, são agenciamentos que aumentam a potência de agir a partir de bons encontros. Conforme dissemos, é uma questão ética e que envolve também a liberdade. Entendamos o corpo do narrador para além de uma reunião de órgãos trabalhando em conjunto, será, como dito, um corpo público, Corpo sem Órgãos que vai ativar agenciamentos produtores de narrativas. São esses afetos que permearão as ações do presente e vão levar o narrador e ouvinte a contraírem os níveis de sua memória. A oralidade característica do Narrador é um dos elementos que auxilia e condiciona a produção de bons encontros, porque exige que se fale e que se escute, que se esteja perto, que se experimente, no lugar de interpretar. Esse lado prático é que vai requerer um justo funcionamento da memória para dar conta da experiência. A tradição não estará escondida no passado, sob o véu empoeirado do tempo. Ela mora no presente porque faz parte do passado e é ativada, atualizada pela memória do narrador e do ouvinte. Isso é a experiência a partir dos encontros, é mergulhar em outras Durações. A já citada parábola do início de "experiência e pobreza"

Oficial da Marinha do Brasil, formado pela Escola Naval, bacharel em Ciências Navais. PósGraduando em Filosofia Contemporânea na Pontifícia Universidade Católica do Rio de Janeiro (PUC-RJ) e Mestrando no Programa de Pós-Graduação em Estudos Marítimos da Escola de Guerra Naval (PPGEM-EGN). Brasileiro, residente no Rio de Janeiro-RJ. Email: 
ilustra bem essa questão. O encontro dos filhos com seu pai inicialmente resultou em uma mera interpretação do conselho paterno. Foi preciso praticá-lo para finalmente experimentá-lo.

Em uma belíssima passagem de "O Narrador" Benjamin resume o que foi explicado até agora:

\begin{abstract}
A rememoração funda a cadeia da tradição, que transmite os acontecimentos de geração em geração. Ela corresponde à musa épica no sentido mais amplo. Ela inclui todas as variedades específicas da forma épica, Entre elas, encontra-se em primeiro lugar a encarnada pelo narrador. Ela tece a rede que em última instância todas as histórias constituem entre si. Uma se liga à outra, como demonstram todos os grandes narradores, principalmente os orientais. Em cada um deles vive uma Sherazade, à qual ocorre uma nova história em cada passagem da história que está contando. Tal é a memória épica, a musa da narração. Mas a esta musa deve opor-se outra, igualmente mais específica, a musa do romance que, no princípio, isto é, na epopéia, ainda se encontra oculta, indiferenciada da musa da narrativa. Porém ela já pode ser pressentida na poesia épica. Acima de tudo nas invocações solenes das Musas, que abrem os poemas homéricos. O que se anuncia nessas passagens é a memória perpetuadora do romancista, em contraste com a breve memória do narrador. A primeira é consagrada a um herói, uma peregrinação, um combate; a segunda a muitos fatos dispersos. Em outras palavras, a reminiscência, musa do romance, surge ao lado da memória, musa da narrativa, depois que a segregação da poesia épica apagou a unidade de sua origem comum na rememoração. (BENJAMIN, 2012, p. 228)
\end{abstract}

Nessa passagem há uma separação clara, uma distinção natural entre duas tendências: A rememoração e a reminiscência. Benjamin associa a primeira à arte de narrar e à poesia época, mas não podemos nos deter na simples comparação formal, excluindo as diferenças e, por isso, encontrando semelhanças. Tal análise seria nos curvarmos a um modelo estruturalista do qual tentamos escapar. Assim, quando Benjamin diz que a musa épica contém a totalidade das formas épicas, tecendo uma rede que conecta todas as histórias em cada uma delas contendo um grande narrador, eis que surge um elemento importante: a coexistência de inúmeras Sherazades todas interligadas e coexistindo, a simultaneidade de uma memória virtual dividida em histórias. São memórias curtas, breves, intensas, e assim devem ser, pois a Oficial da Marinha do Brasil, formado pela Escola Naval, bacharel em Ciências Navais. PósGraduando em Filosofia Contemporânea na Pontifícia Universidade Católica do Rio de Janeiro (PUC-RJ) e Mestrando no Programa de Pós-Graduação em Estudos Marítimos da Escola de Guerra Naval (PPGEM-EGN). Brasileiro, residente no Rio de Janeiro-RJ. Email: 
narrativa precisa antes ser experimentada, precisa haver o encontro, a contingência e, partir dela, atualizações na consciência em forma de valores, de tradições. Tudo não está dado. Por isso a brevidade, porque o que importa aqui é o tempo em intensidade e não em extensão; é um herói, uma peregrinação, um combate: o um, artigo indefinido como a assinatura anônima do narrador, podendo ser um outro, sem ser vários, um herói são uma comunidade de heróis, um combate são infinitos combates, uma peregrinação são tantos Ulisses quanto se quiser... Por outro lado, a reminiscência é o contraposto de tal modelo, dado que procura moldar-se à eternidade sucessiva do tempo, ao atual, de modo que não existe separadamente da rememoração como dois pólos independentes. Ao contrário, Benjamin diz que há um pouco de reminiscência na poesia épica sim, mas seu auge será conhecido quando da evolução do gênero romanesco. A reminiscência ocorrerá como requisição do presente, do tempo prático, tempo moderno.

É bem verdade que a passagem em questão também deixa claro que Benjamin associa a crise da experiência e da narrativa com a ascensão do romance, muito por isso, compara as duas Musas. O gênero romanesco representará o sintoma de evolução técnica culminante, para Benjamin, na Primeira Guerra Mundial. Por evolução técnica podemos entender os instrumentos que substituem o caráter artesanal então presentes na arte narrativa. No lugar de se contar histórias, escrevem-se histórias. Há uma privatização, uma subjetivação, uma individualização do que era comunitário, um enxugamento da Narrativa pelo Romance. A invenção da imprensa, por exemplo, deu margem ao desenvolvimento do comércio de livros e cada indivíduo agora poderia ler quando e como quisesse, no lugar de ouvir. Não seria mais experimentar narrativas, mas sim, interpretar histórias. Alertemos, contudo, que os impactos desse processo não podem ser reduzidos a uma simplória carga moral, ou seja, novamente, não se trata aqui de enaltecer os tempos de outrora em uma nostalgia consensualmente melancólica, assumindo que o "passado" é o que é o certo e deverá ser restaurado. Inclusive, uma 
análise superficial da obra de Benjamin talvez atinja esse lugar comum, porque podemos perceber certo saudosismo em sua prosa. Ocorre que pela própria singularidade de seu estilo, podemos extrair muito mais.

Dessa forma, podemos enxergar até hoje os efeitos desse processo de avanço da técnica. O que seriam hoje as redes sociais se não um resultado conseqüente de tal processo? Cada vez menos se tem a possibilidade de experimentar experiências, pois temos a impressão de que todas já estão dadas. Os agenciamentos produzidos pelos encontros na narrativa benjaminiana deram lugar a agenciamentos de agenciamentos amalgamados em algoritmos a que sequer temos acesso. A Narrativa hoje cedeu lugar a discursos prontos, e, na ilusão de uma liberdade de escolha inebriante, nos detemos apenas a escolher aquilo que já foi escolhido. Tanto o é, que falar de experiência pode, facilmente, ser confundido com postar milimetricamente 0 que se vive através de fotos da sua comida, por exemplo, nos stories do instagram. Contudo, precisamos ir além. Que a técnica ocasionou o declínio da narrativa é verdade, mas como?

\subsection{Como funciona a crise do Narrador}

Ora, uma vez dependente de instrumentos que traduzam a oralidade característica das sociedades arcaicas, o narrador passa a não mais precisar acessar a virtualidade de sua memória para atualizar tradições, minimizando os encontros afetivos. Levando como exemplo a invenção do livro, a própria língua foi equalizada através das padronizações dos dialetos em gramáticas oficiais. Benedict Anderson inclusive aponta esse processo como um dos fatores a condicionar a sensação de uma comunidade imaginada: Fica mais fácil enxergar o outro como igual se, apesar de algumas diferenças em dialetos menores, de uma forma geral, ele fala a mesma língua (ANDERSON, 2012). Com o Romance nos livros a estória do herói precisará ser associada às vivências particulares para serem interpretadas, cultura de vidro. Não mais costumes comunitários atualizados no narrador através de bons encontros, Oficial da Marinha do Brasil, formado pela Escola Naval, bacharel em Ciências Navais. PósGraduando em Filosofia Contemporânea na Pontifícia Universidade Católica do Rio de Janeiro (PUC-RJ) e Mestrando no Programa de Pós-Graduação em Estudos Marítimos da Escola de Guerra Naval (PPGEM-EGN). Brasileiro, residente no Rio de Janeiro-RJ. Email: 
mas aspectos psicológicos modulados pelos predicados de um sujeito. ${ }^{8} \mathrm{Ou}$ seja, o que foi um dia a experiência passou a tornar-se uma virtualidade pela técnica e não pela memória. O salto qualitativo bergsoniano abreviou-se, pois as requisições do presente são tão plurais que não há mais vez para o tédio. Este que Benjamin dizia ser um dos elementos que ativavam a experiência:

\begin{abstract}
O tédio é o pássaro onírico que choca os ovos da experiência. $O$ menor sussurro nas folhagens 0 assusta. Seus ninhos - as atividades intimamente ligadas ao tédio - já se extinguiram nas cidades, e também no campo estão em vias de extinção. Com isso, desaparece o dom de ouvir e desaparece a comunidade dos ouvintes (...) Quanto mais o ouvinte se esquece de si mesmo, mais profundamente se se grava nele o que é ouvido. (BENJAMIN, 2012, p. 221)
\end{abstract}

O homem moderno é um sujeito que age. Ancorado no presente ele precisa encontrar soluções, produzir, trabalhar e ter sucesso para não ficar para trás. Parece que o corpo afetivo se transformou num corpo reativo, e, como resultado, não há espaço para sair de sua própria Duração e explorar outras mais. Mais ainda, nos dias de hoje, o que ocorre, em verdade, é que a produção de subjetividade não se dá somente entre bons encontros entre pessoas, mas também, na pulverização do eu em dados agenciados pelos computadores. Dessa maneira, uma vez mais o salto ontológico é enxugado, porque as reconstituições, de um passado que foi, são frequentemente trazidas à tona, por exemplo, com o próprio facebook relembrando o que ocorrera naquele mesmo dia há alguns anos: sequer precisamos acessar a memória, porque ela fora engessada no pretérito perfeito e materializada pela fotografia.

\footnotetext{
${ }^{8}$ É bem verdade que bons encontros não se resumem a encontros com outra pessoa, o que muitas vezes resulta no oposto. Mas o que se quer deixar claro aqui é a mudança de tendência entre os agenciamentos que se tinham com pessoas e agora com os resultantes de artefatos produzidos pela técnica.
}

Oficial da Marinha do Brasil, formado pela Escola Naval, bacharel em Ciências Navais. PósGraduando em Filosofia Contemporânea na Pontifícia Universidade Católica do Rio de Janeiro (PUC-RJ) e Mestrando no Programa de Pós-Graduação em Estudos Marítimos da Escola de Guerra Naval (PPGEM-EGN). Brasileiro, residente no Rio de Janeiro-RJ. Email: 


\section{CONCLUSÃO}

Com o fito de reformular o problema do tempo, pudemos perceber a intensa ressonância que a obra de Walter Benjamin desencadeia. É bastante interessante observar a singularidade de seus ensaios, porque com eles podemos realizar múltiplas conexões, para além do mero formalismo dialético a que estamos, com frequência, submetidos. O conceito de Experiência não está fadado a uma economia discursiva convergente para um único significado que circunscreva todas as suas multiplicidades. Ao contrário, pudemos ver o quanto a sua abertura permite uma intensa expressividade quando associado aos conceitos de Deleuze, Guattari e Bergson e, mais ainda, o quanto nos possibilita acessar a paradoxal coexistência entre passado e presente.

Duração, tempo e memória são temas fundamentais e precisam ser relacionados ao que Benjamin entende pela arte de Narrar. Isso posto, conseguimos entender um pouco do próprio funcionamento das sociedades de controle. Assinalamos que o intuito desse trabalho não poderá ser resumido a uma solução ou fórmula que dê conta do tempo. Tal intento seria recair em um falso problema. Nos parece muito mais filosófico reformular o que a filosofia entende por si mesma, do que atribuir diferenças de grau a um todo já constituído e continuar o que já está dado. Concordamos com a contemporaneidade de Nietzsche nesse sentido. Por isso, procuramos entender muito mais o funcionamento do que o significado do tempo e da memória do Narrador.

\section{REFERÊNCIAS}

ANDERSON, Benedict. Comunidades Imaginadas. São Paulo: Cia das Letras, 2012.

ARENDT, Hannah. Homens em tempos sombrios. Tradução Denise

Bottmann. São Paulo: Companhia das Letras, 2008 
BENJAMIN, Walter. Magia e técnica, arte e política: ensaios sobre literatura e história da cultura. Trad. Sérgio Paulo Rouanet. 8a. Edição. São Paulo: Brasiliense, 2012

BERGSON, Henri. A Evolução Criadora. São Paulo: Editora Unesp, 2009. Matéria e Memória: ensaio sobre a relação do corpo com o espírito.Trad. Paulo Neves. $4^{a}$ Edição. São Paulo: WMF Martins Fontes, 2010.

DELEUZE, Gilles/GUATARRI, Felix. Mil Platôs: capitalismo e esquizofrenia 2 Vol 4. Trad. Suely Rolnik. São Paulo: Editora 34, 2012.

Bergsonismo. Trad. Luiz B. L Orlandi. São Paulo: Editora 34, 2012.

Nietzsche. Lisboa: Edições 70 LTD, 2016. 